\title{
A note on evaluating VAN earthquake predictions
}

\author{
G-Akis Tselentis and Nicos S. Melis \\ Seismological Laboratory, Department of Geology, University of Patras, Greece
}

\begin{abstract}
The evaluation of the success level of an earthquake prediction method should not be based on approaches that apply generalized strict statistical laws and avoid the specific nature of the earthquake phenomenon. Fault rupture processes cannot be compared to gambling processes. The outcome of the present note is that even an ideal earthquake prediction method is still shown to be a matter of a "chancy" association between precursors and earthquakes if we apply the same procedure proposed by Mulargia and Gasperini [1992] in evaluating VAN earthquake predictions. Each individual VAN prediction has to be evaluated separately, taking always into account the specific circumstances and information available. The success level of epicenter prediction should depend on the earthquake magnitude, and magnitude and time predictions may depend on earthquake clustering and the tectonic regime respectively.
\end{abstract}

\section{Suggestion}

With this short note we would like to add our point of view towards evaluating VAN's results. We believe that before attempting to criticize the results of a new theory which is mainly based on experimental measurements we should: (a) repeat the experimental procedures independently, (b) establish a reliable database on which to base the evaluation of the theory, and (c) decide about the rules of the game upon which the evaluation will be based.

Unfortunately, during the past few years we have seen in the literature some papers which attempted to criticize VAN's theory based either on some simplified comparison of seismic catalogues with the predicted events [Drakopoulos et al., 1994] or on the application of some generalized statistical assumptions (wrong "rules of the game") avoiding the specific nature of the seismological data [Mulargia and Gasperini, 1992], cited hereafter as $\mathrm{MG}$.

We should always remember that predicting an earthquake is predicting its magnitude, its location and its time of origin, of course within a tolerance. Any method which is attempting to evaluate the accuracy of a prediction based on generalized ("generalized suit fits nobody") strict statistical rules and also avoiding the

\section{Copyright 1996 by the American Geophysical Union}

Paper number 96GL.00585

0094-8534/96/96GL-00585\$05.00 special character of the earthquake phenomenon is questionable.

\section{Possible "rules of the game" for evaluating an earthquake prediction method}

In order to evaluate an earthquake prediction method, the three parameters determining the earthquake phenomenon (i.e. epicenter, time of occurrence and magnitude) should be all considered with great care.

As far as the epicenter is concerned, the success level of each prediction should take into account the corresponding earthquake magnitude. A tolerance of $50 \mathrm{~km}$ adopted by Varotsos et al. [1996] is certainly too large for a 4.0R event and to small for a $6.5 \mathrm{R}$ event. Earthquake point sources exist only in theory and we should assess the tolerance limit from a formula which will depend on the magnitude $M$ :

$$
\Delta \mathrm{r}(\mathrm{M})=\mathrm{L}(\mathrm{M})+\text { tolerance }
$$

where $L$ is the rupture length which can be estimated from an equation of the following form:

$$
\log L=a+b M
$$

As far as the magnitude is concerned we should restrict our evaluation to (considering the background seismicity) earthquake magnitudes greater than a threshold magnitude $M_{0}$ and certainly exclude all foreshock or aftershock sequences from the dataset under consideration. Obviously, there is no point in a seismically active region to deal with the prediction of low magnitude events (the number of which increases drastically towards lower magnitudes according to the Gutenberg - Richter law). We shall mention here that the earthquake catalogue on which MG based their statistics contains a significant amount of aftershock data (Fig. 1), something that makes their statistics questionable since the basic assumption of a Poisson distribution (that of independent events) is violated.

The third important parameter which should be incorporated into the evaluation of a prediction is the time of occurrence of the earthquake. Certainly, we should not adopt a constant time interval within which to restrict the successful predictions. Earthquake processes do not obey time zones. We should not forget that some large events are preceded by foreshocks and some do not. The time parameter can be dependent of the tectonic regime within which the earthquake process takes place. 


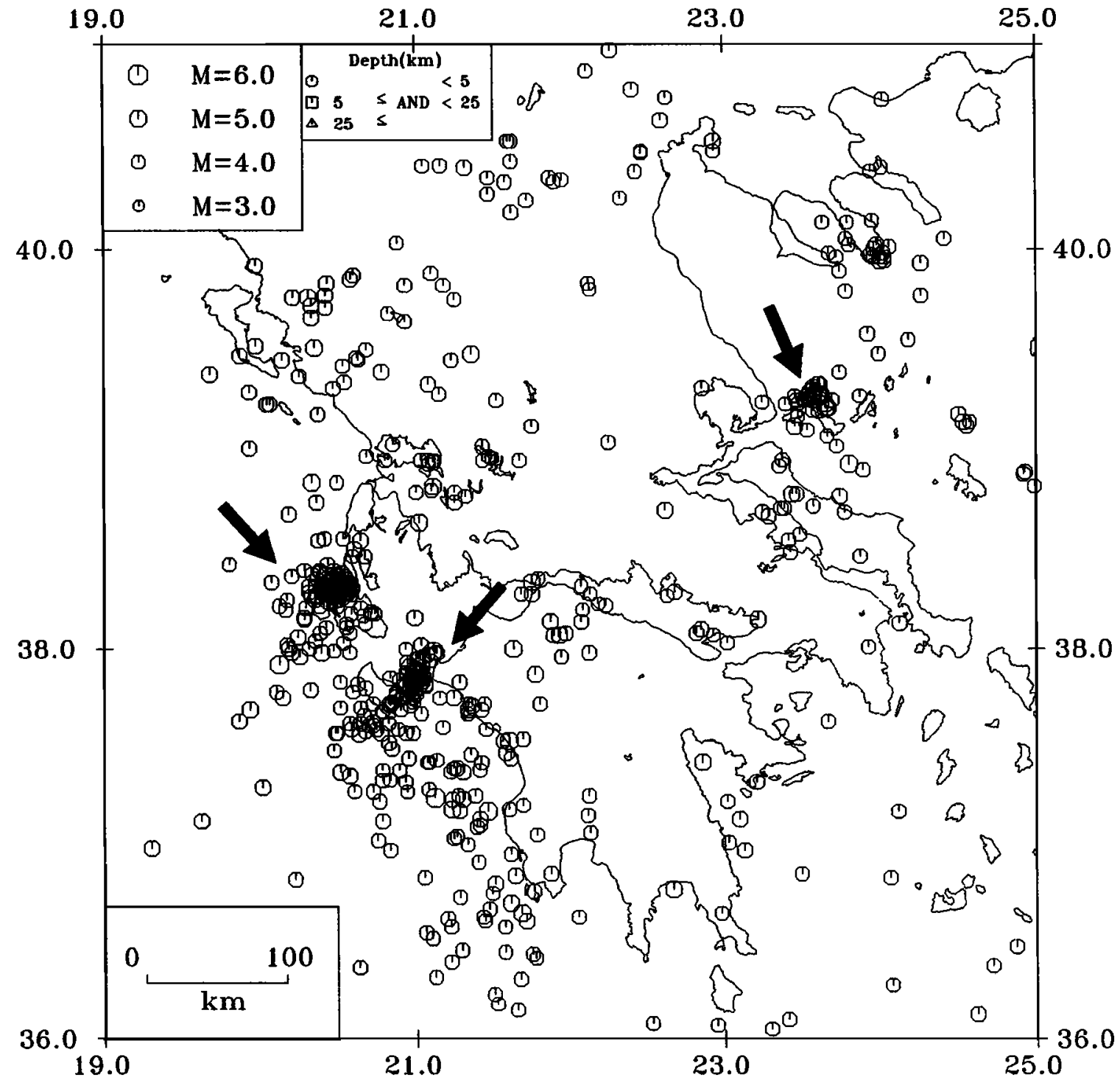

\section{Events}

Figure 1. Epicentral distribution of the events analyzed by MG. The arrows indicate the different clusters of events, which correspond to the same earthquake sequence. $M$ refers to $M_{s}$.

\section{Evaluating an ideal earthquake prediction method (IEPM) by adopting the MG procedure}

In the following, we will demonstrate that using a similar procedure as the one proposed by MG, results in the conclusion that even an ideal earthquake prediction method (IEPM) is still a matter of "chancy" association between precursors and earthquakes.

A three year time window (1983-1985; i.e. $T \approx$ 1100 days) for the same homogeneous area as the one taken by $\mathrm{MG}\left(36-41^{\circ} \mathrm{N}, 19-25^{\circ} \mathrm{E}\right)$ was extracted from the Makropoulos et al. [1989] catalogue (Fig. 2). For the selected time window the catalogue is complete for earthquakes of magnitude $M_{s} \geq 4.0$. A total of 330 events with magnitude $M_{s} \geq 4.0$ was extracted from the catalogue. Table 1 presents the number of events for the range of magnitudes which will be used with the MG statistical procedure.
Thus, following the MG statistical procedure we considered an IEPM which announces predictions for events of expected magnitude $M_{s} \geq 5.0$. Following also their "rules of the game," in space (because the epicenter is predicted correctly) we suppose an ideal prediction with a tolerance of $\Delta \mathrm{r} \approx 0 \mathrm{~km}$, in time we adopt the window of $\Delta t \leq 22$ days and we consider as possible to be accurately predicted all the events with magnitude $M_{s} \geq$ 5.3. Next we calculate the significance level from the usual expression Poissonian expression (Eq. A.9 of MG; see also Varotsos et al. [1996] (Eq. 1 this issue) and the obtained results are depicted in Table 2 and Table 3, in correspondence with Table 1 and Table 2 of MG respectively.

In both Tables 2 and 3, the significance level does not even near reach down to the value of 0.05 , which according to the statistical decision theory is the upper bound value for significance level of an association (i.e. 


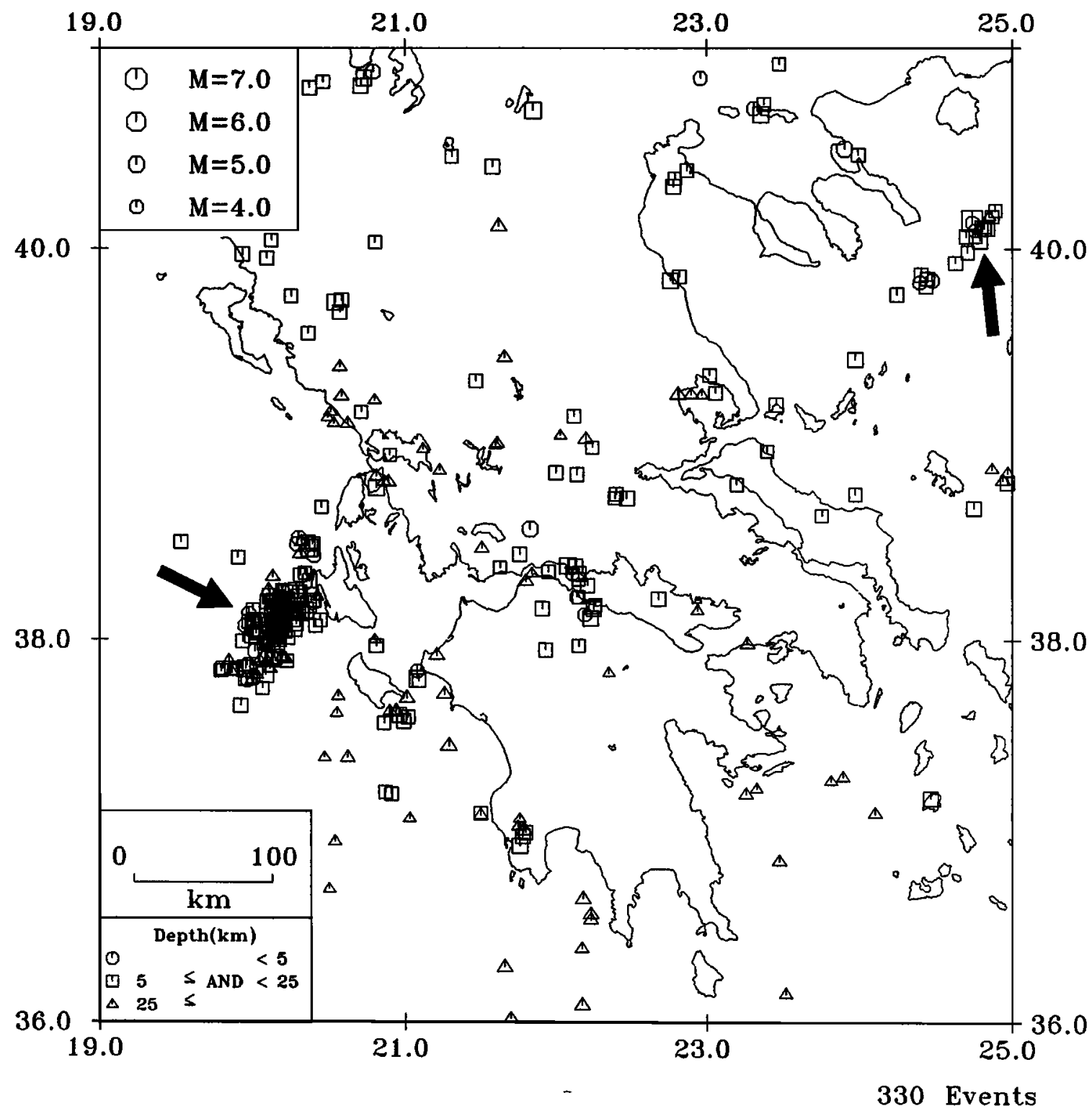

Figure 2. Epicentral distribution of events extracted from the Makropoulos et al. [1989] catalogue in order to try the IEPM according to the MG procedure. Note that $M$ refers to $M_{s}$. As in Fig 1, arrows indicate the clusters of events, which correspond to an earthquake sequence.

precursors with earthquakes) which would stand beyond chance.

\section{Conclusions and recommendations}

Evaluating the success level of an earthquake prediction should not be based on the "generalized suit"

Table 1. Number of events extracted from the Makropoulos et al. [1989] catalogue for the different $M_{s}$ magnitude ranges used in the statistical analysis

\begin{tabular}{|c|c|c|c|}
\hline $\begin{array}{c}\text { Magnitude } \\
\left(\mathrm{M}_{\mathrm{s}}\right)\end{array}$ & $\begin{array}{l}\text { Number } \\
\text { of events }\end{array}$ & $\begin{array}{c}\text { Magnitude } \\
\left(\mathrm{M}_{\mathrm{s}}\right)\end{array}$ & $\begin{array}{l}\text { Number } \\
\text { of events }\end{array}$ \\
\hline $\mathrm{M} \geq 4.3$ & 164 & $M \geq 5.1$ & 29 \\
\hline$M \geq 4.6$ & 93 & $M \geq 5.3$ & 17 \\
\hline$M \geq 4.8$ & 56 & $M \geq 5.5$ & 10 \\
\hline$M \geq 5.0$ & 41 & $M \geq 5.8$ & 3 \\
\hline
\end{tabular}

Table 2. Evaluating an IEPM following the MG procedure rules of the game: Magnitude of Predictions $\pm 0.7, \Delta \mathrm{t} \leq 22$ days, $\Delta \mathrm{r} \approx 0 \mathrm{~km}$

\begin{tabular}{llrrrr}
\hline $\begin{array}{c}\text { Prediction } \\
\text { range }\end{array}$ & $\begin{array}{c}\text { Total } \\
\text { pred. }\end{array}$ & $\begin{array}{c}\text { Correct } \\
\text { pred. }\end{array}$ & $\begin{array}{c}\text { Num. of } \\
\text { events }\end{array}$ & $\mu$ & $\begin{array}{l}\text { Sign. } \\
\text { level }\end{array}$ \\
\hline All & 38 & 38 & $330^{*}$ & 250.80 & 1.000 \\
$M \geq 5.0$ & $38^{* *}$ & 38 & $164^{* * *}$ & 124.64 & 1.000 \\
$M \geq 5.3$ & $23^{* *}$ & 23 & $93^{* * *}$ & 42.78 & 1.000 \\
$M \geq 5.5$ & $8^{* *}$ & 8 & $56^{* * *}$ & 8.96 & 0.671 \\
$M \geq 5.8$ & $5^{* *}$ & 5 & $29^{* * *}$ & 2.90 & 0.168 \\
\hline
\end{tabular}

* The number 330 corresponds to the whole dataset of events with magnitude $M_{8} \geq 4.0$.

** All predictions with $M_{s} \geq M$ where $M$ the value of the 1st column. All predictions are assumed correct in the 3rd column.

*** All earthquakes with magnitude $\mathrm{M}_{\mathrm{s}} \geq \mathrm{M}-0.7$. 
Table 3. Evaluating an IEPM following the MG procedure rules of the game: Magnitude of Earthquakes $\pm 0.7, \Delta \mathrm{t} \leq 22$ days, $\Delta \mathrm{r} \approx 0 \mathrm{~km}$

\begin{tabular}{llrlrl}
\hline $\begin{array}{c}\text { Magnitude } \\
\text { range }\end{array}$ & $\begin{array}{c}\text { Total } \\
\text { pred. }\end{array}$ & $\begin{array}{c}\text { Correct } \\
\text { pred. }\end{array}$ & $\begin{array}{c}\text { Num. of } \\
\text { events }\end{array}$ & $\mu$ & $\begin{array}{l}\text { Sign. } \\
\text { level }\end{array}$ \\
\hline All & 38 & 38 & $330^{*}$ & 250.80 & 1.000 \\
$M \geq 5.0$ & $38^{* *}$ & 38 & $41^{* * *}$ & 31.16 & 0.129 \\
$M \geq 5.3$ & $38^{* *}$ & 17 & $17^{* * *}$ & 12.92 & 0.159 \\
$M \geq 5.5$ & $38^{* *}$ & 10 & $10^{* * *}$ & 7.60 & 0.235 \\
$M \geq 5.8$ & $26^{* *}$ & 3 & $3^{* * *}$ & 1.56 & 0.206 \\
\hline
\end{tabular}

* The number 330 corresponds to the whole dataset of events with magnitude $M_{s} \geq 4.0$.

** All predictions were issued with $\mathrm{M}_{\text {pred }} \geq \mathrm{M}-0.7$ where $M$ the value of the 1 st column. All predictions are assumed correct in the 3rd column and also predictions were issued for events expected with $M_{s} \geq 5.0$

*** All earthquakes with magnitude $M_{s} \geq M$. Note also that earthquakes with $M_{s} \geq 5.3$ have been all predicted by the IEPM.

approach by applying strict statistical laws and avoiding the specific nature of the earthquake phenomenon. Geological processes and specially the rupture of earthquake faults cannot be compared to gambling processes.

Sometimes an earthquake prediction is a result of a multidisiplinary effort considering various precursor phenomena. For example we might evaluate the time window within which an event will occur from SES signals, and we might restrict the epicentral region from a sudden increase in microearthquake activity (we have several examples of this kind in our territory). This should be considered into the evaluation process. It should not be ignored the case of the Grevena - Kozani, northern Greece, earthquake (May 13, 1995; $M_{L}=6.1$ ) that devastated several villages and towns in a region where statistics failed for long term prediction approaches, as no seismicity was reported by any existing earthquake catalogue covering historic and recent times.

During the last 3 years we have established and operated an earthquake prediction lab at one of the most seismically active regions of Europe (W. Greece). One of the major research tasks has been the experimental evaluation of the VAN method [Tselentis and Ifantis, 1993]. During this period we have recorded a great number of SES well related to the seismicity of the region. The results concerning this matter are the subject of a separate publication [Tselentis and Ifantis, 1996].

\section{References}

Drakopoulos, J., G. Stavrakakis, and J. Latoussakis, Physical properties of the variation of the electric field of the earth preceding earthquakes-discussion, Tectonophysics, 161, 55-57, 1989.

Makropoulos, K. C., J. K. Drakopoulos, and J. B. Latoussakis, A revised and extended earthquake catalogue for Greece since 1900 , Geophys. J. Int., 98, 391-394, 1989.

Mulargia, F., and P. Gasperini, Evaluating the statistical validity beyond chance of VAN earthquake precursors, Geophys. J. Int., $111,32-44,1992$.

Tselentis, G-A, and A. Ifantis, Self-potential variations with time and their possible relation with seismic activity in western Greece, Acta Geophys. Pol., XILI, 269-279, 1993.

Tsenentis, G-A, and A Ifantis, Some distinctive examples of geoelectric variations as related to earthquakes obtained during a three year independent VAN experimental investigation, Geophys. Res. Lett., this issue, 1996.

Varotsos, P., K. Alexopoulos, and M. Lazaridou, Latest aspects of earthquake prediction in Greece based on seismic electric signals. Tectonophysics, 224, 1-37, 1993.

Varotsos, P., K. Eftaxias, F. Vallianatos, and M. Lazaridou, Basic principles for evaluating an earthquake prediction method, Geophys. Res. Lett., this issue, 1996.

G-Akis Tselentis and Nicos S. Melis, Seismology Laboratory, Department of Geology, University of Patras, GR-261 10 Rio, Greece. (e-mail: tselenti@upatras.gr).

(received May 30, 1994; revised February 14, 1996; accepted February 15, 1996) 